Original Research Paper

\title{
Preparation of Porous Silicon P-Type and Thermal Diffusivity Measurement Using Photoacoustic Technique
}

\author{
Mohammed Jabbar Hussein, Suaad Sahib Hindal and Amany Akram Awaad \\ Laser and Electro-Optic Centre, Directorate of Material Research, Ministry of Science and Technology, Iraq
}

\author{
Article history \\ Received: 10-01-2018 \\ Revised: 26-02-2018 \\ Accepted: 10-04-2018 \\ Corresponding Author: \\ Mohammed Jabbar Hussein \\ Laser and Electro-Optic Centre, \\ Directorate of Material \\ Research, Ministry of Science \\ and Technology, Iraq \\ E-mail: mohammed55865@yahoo.com
}

\begin{abstract}
Porous silicon (PSi) layers were formed on a p-type Si wafer. Electrochemical method was used to prepare 36 samples with three values of current density $(10,20$ and 30$) \mathrm{mA} / \mathrm{cm}^{2}$, each involved $(20,40,60$ and 80) min etching times the samples were heated to three selected temperatures of 100,200 and $350^{\circ} \mathrm{C}$ in three groups. The first group covers 12 samples corresponding to $10 \mathrm{~mA} / \mathrm{cm}^{2}$ while the other two correspond to the remaining values of current density respectively. Each annealing process for these sample groups lasted three hours in ambient air. The morphology of the layers, before and after annealing, formed by this method was investigated by Scanning Electron Microscope (SEM). Photoacoustic technique (PA) was employed carry out Thermal Diffusivity (TD) measurements. In this study, the porosity and thickness porous increased with increasing current density and etching time. While the thermal diffusivity TD increases with increasing annealing temperature.
\end{abstract}

Keyword: Porous Silicon, Photoacoustic, Thermal Diffusivity, Etching Time, Current Density

\section{Introduction}

The principle of Photoacoustic (PA) effect has been studied for over a century. The first phenomena of PA technique were first proposed by Alexander Graham Bell in 1880 (Favier, 1997). The PA effect in condensed matter may be detected by microphone by impinging modulated light on a solid sample surface which in turn produces heat on the sample surface. The resulting heat causes pressure waves to be created in the chamber housing both gas and sample where this pressure produces acoustic signal in the chamber (Almond and Patel, 1996). Rosencwing and Gersho (RG) derived a one-dimensional theory for the PA effect from a solid material, known as the R-G theory, which has formed the founding principles of other theories on microphone PA detection from solid sample (Rosencwaig and Gersho, 1976). Bennett (McDonald and Wetsel, 1978) used the Navier-Stokes equations as tool to modify the existing model for acoustic wave transport in a gas. Perondi used a new technique called Open Photoacoustic Cell (OPC) via thermally induced vibrations in samples confirming the use of open cell PA technique for thermal characterization of solid and liquid samples (Perondi and Miranda, 1987). RG theory one dimensional heat flow model has been greatly modified to form strong background platform for this technique (Aamodt and Murphy, 1981). RG theory for acoustic detection technique uses both gas condenser and microphone for pressure variation detection in air. According to RG theory, from the rear samples, the thermally thick PA signal amplitude decreases exponentially with modulation frequency as (Raveendranath et al., 2006):

$$
P A_{\text {thick }}=\frac{A}{f} e(-b \sqrt{f})
$$

where, $\quad b=l_{s} \sqrt{\frac{\pi}{a_{s}}}$ and $l_{\mathrm{s}}$ is thickness of sample $A$ is constant, $f$ is frequency:

$a_{s}=\pi\left(\frac{l_{s}}{b}\right)^{2}$

$\alpha_{s}=$ The thermal diffusivity of the sample

PSi was found to have large surface area which is very useful in crystalline surface spectroscopy. Due to these findings, there was an increased interest in researches concerning PSi in the 1970s and 1980s (Gupta et al., 1991). It is used in the generation of thin oxide pattern on $\mathrm{Si}$, and also a dielectric cover on chemical sensors. Canham, (19901995) showed how he used his red luminescence result obtained from PSi involving nanocrystals of $\mathrm{Si}$ in pore walls. The research by Canham has greatly influenced the growing interest in the use of PSi material. Further finding on the efficient visible light emission from PSi stimulated 
more studies on optoelectronic based Si switches, displays, and lasers. Over the past twenty years, the optical properties of PSi have been vigorously researched (Bisi et al., 2000). PSi has some unique properties ranging from perfect mechanical and thermal properties which are compatible with microelectronics prepared from $\mathrm{Si}$, large surface area, fine tuning sizes, surface chemistry, cost-effectiveness and tunable refractive index as a function of depth (Striemer and Fauchet, 2002). Thermal Diffusivity (TD) measurement for silicon $\mathrm{n}$ and $\mathrm{p}$ type with high annealing temperature using photoacoustic technique (Hussein et al., 2015a). Preparation and thermal characterization of annealed gold coated PSi layers grown on a p-type Si wafer (Behzad et al., 2012). PA technique was used to study the optical absorption and energy band gap of PSi. electrochemical anodization etching technique was used to prepare PSi layers on p-type Si wafers with different current density (El-Brolossy, 2012). energy band gap was measured for p-type PSi using photolumencence (Hussein et al., 2016). Electrochemical method was used to prepared $\mathrm{p}$-type PSi with different current density and varying etching time for TD measurement (Hussein et al., 2016). In this work, TD for porous p-type Si prepared by electrochemical method was measured using photoacoustic technique under high annealing temperature.

\section{Methodology}

The samples used in this study are p-type silicon wafer supplied by Valley Microelectronics Company and has orientation (100) and $521 \mu \mathrm{m}$ thick. The wafer was cut into a square form $(2 \times 2 \mathrm{~cm})$ and used electrochemical method to prepare porous silicon under different etching times (20, 40, 60 and $80 \mathrm{~min}$ ) with three values of current density $(10,20$, and $30 \mathrm{~mA} / \mathrm{cm}^{2}$ ). All samples were annealed by heating in air to temperatures $(100,200$ and 350$){ }^{\circ} \mathrm{C}$. The annealing or heating time at each temperature is three hours. The experimental set up used in the present study is schematically shown in Fig. 1. The setup consists of a HeNe laser beam (MellesGriot, model 05LHR828) which has output power $75 \mathrm{~mW}$ and wavelength $632 \mathrm{~nm}$ light source, was modulated with mechanical optical chopper (SR540) from $4 \mathrm{~Hz}$ to $4 \mathrm{kHz}$. The laser beam was focused onto the sample after being mechanically chopped by an optical chopper kept inside the OPC cell. As a result of the periodic heating, the heat generated in the sample is transferred to the gas in contact. Hence, the air in the chamber oscillates at the chopping frequency, causing diaphragm deflection, which generates a voltage across the load resistor. The signal detected by a microphone in OPC is amplified by a low noise pre-amplifier (SR560) with a variable frequency bandwidth and gain that has filter ranges from 0 to 5000 $\mathrm{kHz}$. The amplified PAS then is passed to a lock-in amplifier (SR530) to analyze and convert it into PA spectroscopy amplitude and phase. Data collocation was established by LabVIEW software and then magnitude and phase were analyzed by Origin lab 8 software.
Figure 2 shows the cross section of an Open Photoacoustic Cell (OPC). This represents the main part of the PAS the cell functions is to generate and detect the acoustic signal. The PA cell was manufacture from Aluminum with outer diameter of $8.30 \mathrm{~cm}$ and height of $3.50 \mathrm{~cm}$. The inner cylindrical cell was $1.20 \mathrm{~cm}$ in breadth, $2.50 \mathrm{~cm}$ in length, and diameter of the circular opening 0.60 $\mathrm{cm}$. The cell was built with electrets microphone in the cell and it is mounted at the second metal plate. The microphone (electrets microphone COM-08635 ROHS) acts as pressure sensor to detect the acoustic signal.TD for PSi samples can be obtained by fitting the experimental data with Equation 1 of thermally thick region for $b$ and from this, TD can be evaluated from Equation 2. TD measurements were carried out by the PA technique using OPC technique and repeated three times to ensure the consistency of the value at room temperature. The morphological characterizations of the sample surface were carried out by using Scanning Electron Microscopy (SEM).

\section{Preparation of Porous Silicon}

There are two methods used for preparing PSi wafers which are based on crystalline $\mathrm{Si}$ and referred to as chemical and electrochemical. In the electrochemical method, an external voltage source is required for biasing and associated processes while in the other, etching is usually performed by a chemical process only. In addition to the above- mentioned specifications, the PSi samples had an electrical resistivity of about $1-10 \Omega \mathrm{cm}$ prior to preparation, the wafers were cleaned and cut into approximately $2 \mathrm{~cm}$ square as substrates. The cleaning of substrates were done by sonification for $5 \mathrm{~min}$ in ethanol, acetone and diluted HF in ethanol. Si samples substrate were placed on an aluminum plate and both were located at the bottom of the cylindrical which acted as an anode a. A platinum rod, used as cathode, was centered on the top of the cell with an electrode separation of $(1 \mathrm{~cm})$. The optimum porosity was obtained by using a solution of $99.90 \%$ ethanol purity in a ratio of $1: 1$ with $\mathrm{HF}\left(\mathrm{HF}: \mathrm{C}_{2} \mathrm{H}_{5} \mathrm{OH}\right)$. The $\mathrm{HF}$ aside is an essential ingredient for the anodical etching of Si. Ethanol was added into electrolyte to enhance the homogeneity and uniformity of the PSi surface, since it acts as a promoting agent to increase wettability into PSi surface and to remove the extraneous $\mathrm{H}_{2}$ bubbles that appear during the anodical etching process. Clearly, ethanic solutions permit the formation of uniform and deep pores of the PSi layer while a purely aqueous solution does not. A digital DC current source (ADCMT6243) was used to supply a constant current. Figure 3 shows a schematic diagram of all materials used for the preparation of PSi. To generate the electron hole pairs, the surface of sample was illuminated during the anodisation using a $300 \mathrm{~W}$ halogen lamp (Osram, ELH93518). For all samples, a voltage of 50V was applied to the halogen lamp for illumination. Samples were subjected to under densities of 10,20 and $30 \mathrm{~mA} / \mathrm{cm}^{2}$, and etching times about 20, 40,60 and $80 \mathrm{~min}$. 


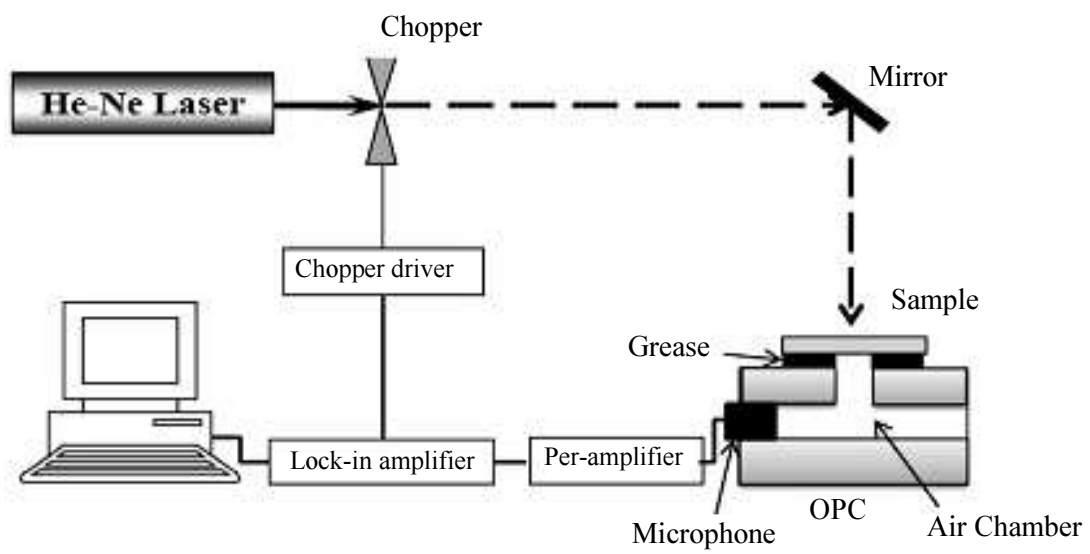

Fig. 1: Experimental set-up of the open photoacoustic cell detection technique

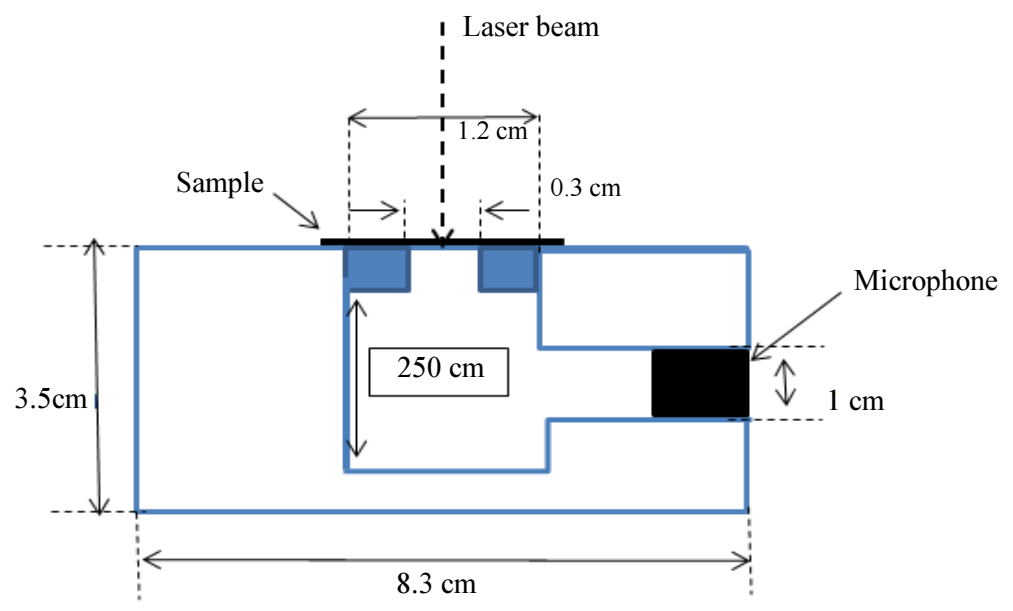

Fig. 2: Cross section of an Open Photoacoustic Cell (OPC)

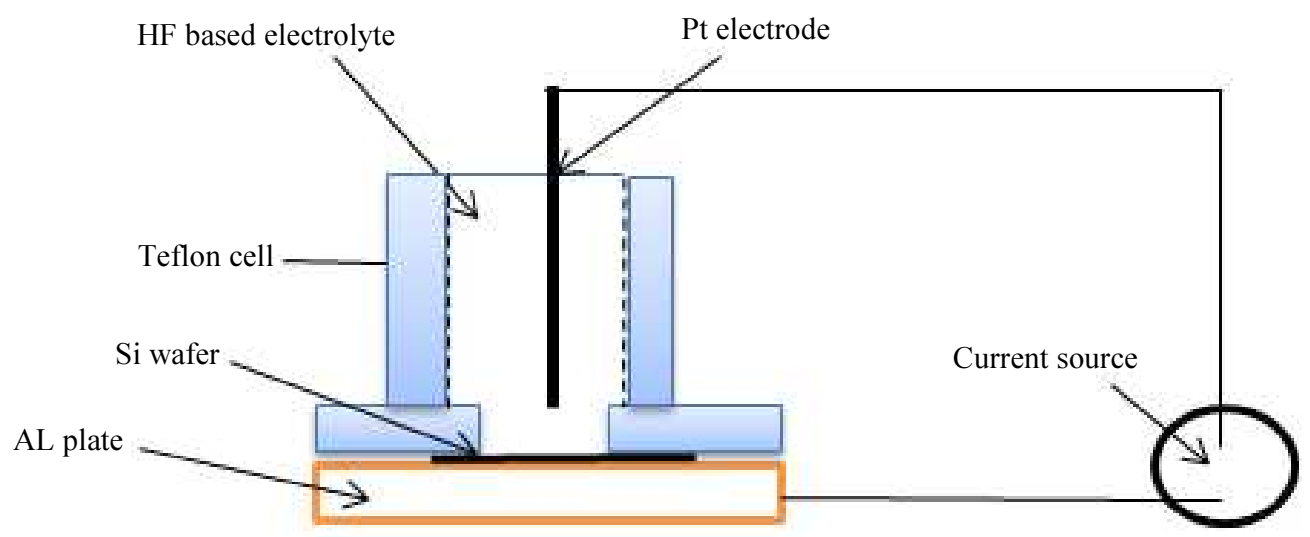

Fig. 3: Schematic diagram of the electrochemical etching cell for anodisation

\section{Results and Discussion}

The porosity is defined as a fraction of the void in the PSi layer and can be easily obtained by measuring the weight. A wafer is weighed before porous $m_{1}$, just after porous $m_{2}$, and after removing the porous layer in a $3 \%$
Sodium hydroxide $(\mathrm{NaOH})$ solution $m_{3}$. Porosity is then given as:

$$
P(\%)=\frac{m_{1}-m_{2}}{m_{1}-m_{s}}
$$


where, the $P$ is the porosity.

The porous thickness was measured by a profilometer (Ambios Technology, XP-200). Sample thickness and porosity were calculated by the gravimetric method. The porosity and thickness were found to increase with increasing current density and etching time.

Porous silicon samples were prepared by electrochemical method under three sets of current density $\left(10,20\right.$ and $\left.30 \mathrm{~mA} / \mathrm{cm}^{2}\right)$ and different etching time (20, 40, 60 and $80 \mathrm{~min})$. The porosity of the PSi samples can be obtained using Equation 4. The result shown porosity in this experimental increased from 20.3 to $78.2 \%$ also the thickness porous from 4 to $58.8 \mu \mathrm{m}$ these results show that porosity was initially increased (Hussein et al. 2015b) and then the increment is found slow for porosity after $40 \mathrm{~min}$ because of the silicon structure is ready to porous and the porosity is high when the current density is higher. The photoacoustic technique was used to measure TD for the PSi under annealing temperature from 100 to $350^{\circ} \mathrm{C}$. The heating temperatures were chosen as 100,200 and $350^{\circ} \mathrm{C}$ and the heating time is $3 \mathrm{~h}$. Figure $4 \mathrm{a}-\mathrm{f}$ shows the relationship between PAS and modulation frequency according to
RG theory. The thermally thick region for the sample Equation 1; PAS decreased exponentially with the modulation frequency. TD measurement of p-type PSi samples which have a thickness of $521 \mu \mathrm{m}$ were measured using OPC technique cell by fitting the experimental data with equation 1 of thermally thick region for $b$ and TD can be evaluated from Equation 2. Table (1) shows the total TD results decreased when the temperature increases because the phonon free bath is longer when the temperature is elevated which leads to increasing resistivity and decreasing TD. The results indicate that average TD decreases $0.00133 \mathrm{~cm}^{2} / \mathrm{s}$ for the sample $\mathrm{J}=10 \mathrm{~mA} / \mathrm{cm}^{2}$ and $\mathrm{t}=$ $20 \mathrm{~min}$ and average TD $0.0524 \mathrm{~cm}^{2} / \mathrm{s}$ for the samples $\mathrm{J}$ $=10 \mathrm{~mA} / \mathrm{cm}^{2}$ and $\mathrm{t}=80 \mathrm{~min}$. For structural characterization, the PSi layers were examined with Scanning Electron Microscopy (SEM) before and after annealing for different samples. Images show the PSi layer prepared on a $\mathrm{Si}$ substrate. Porous silicon structures were seen clearly on the top view in Fig. 5-a porous silicon structure before annealing Fig. 5b-d) the structure porous after annealing with the same three temperatures for three hours heating.

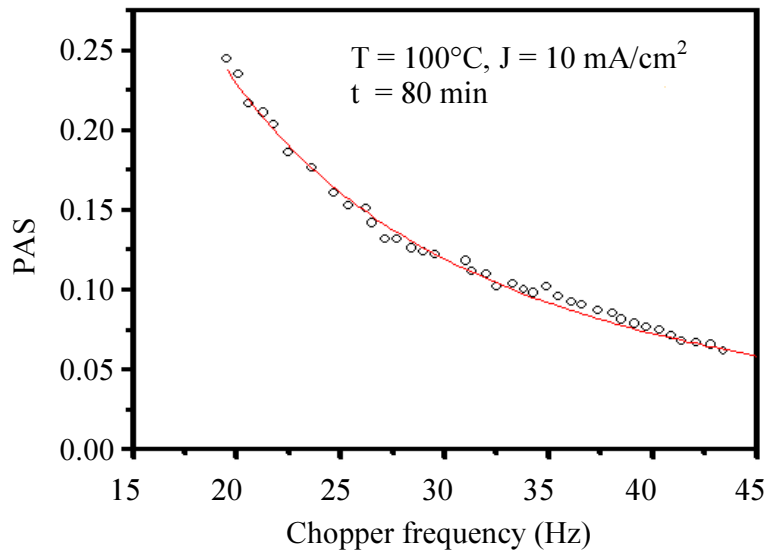

(a)

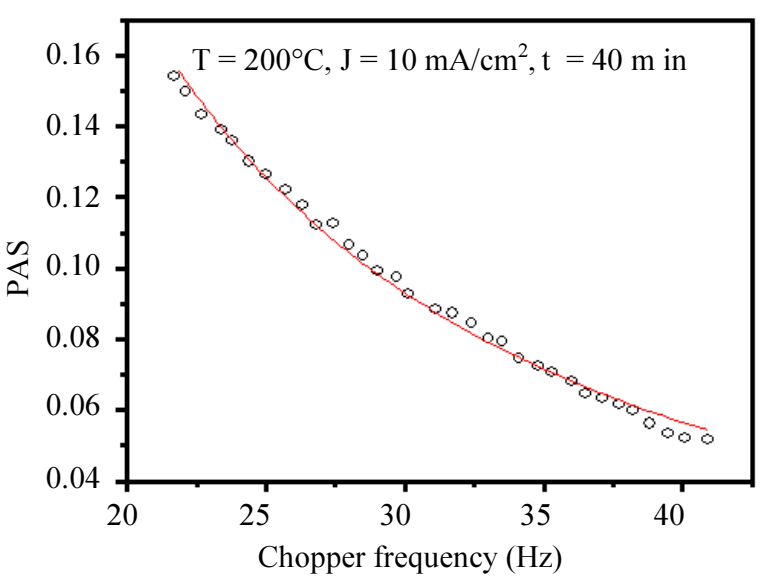

(c)

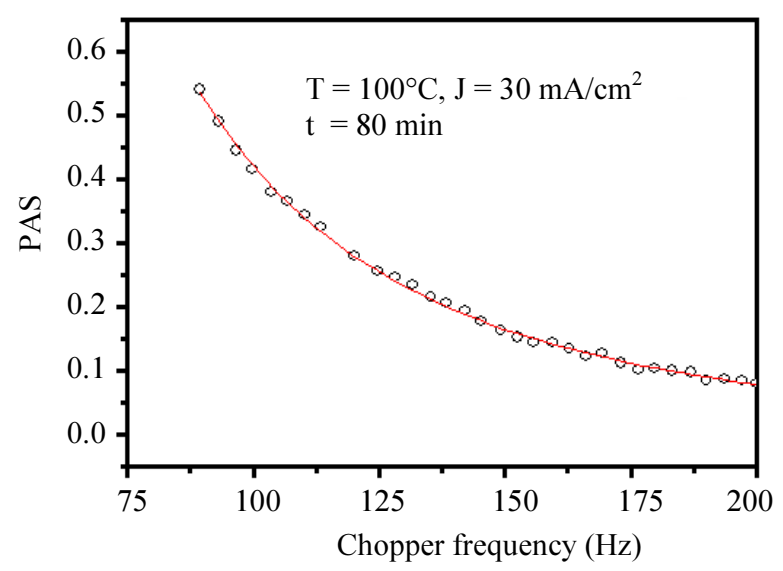

(b)

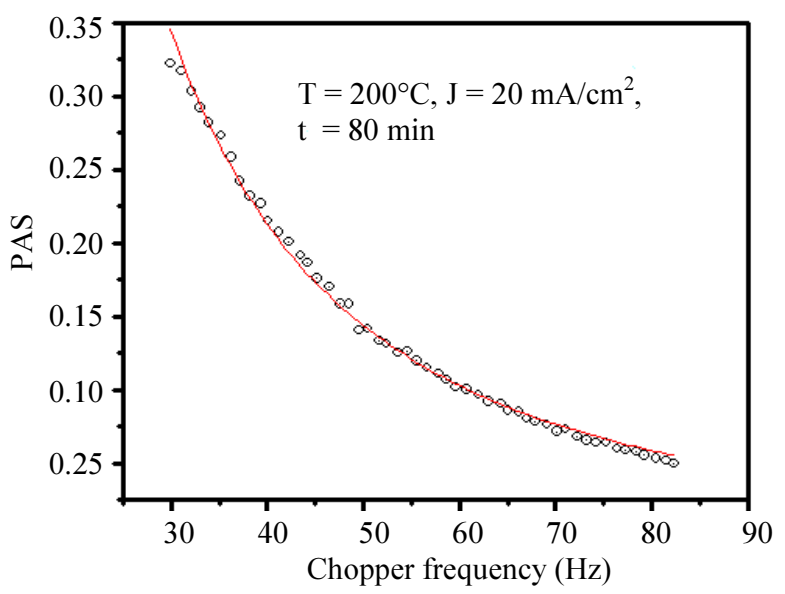

(d) 
Mohammed Jabbar Hussein et al. / International Journal of Structural Glass and Advanced Materials Research 2018, Volume 2: 191.197 DOI: $10.3844 /$ sgamrsp.2018.191.197

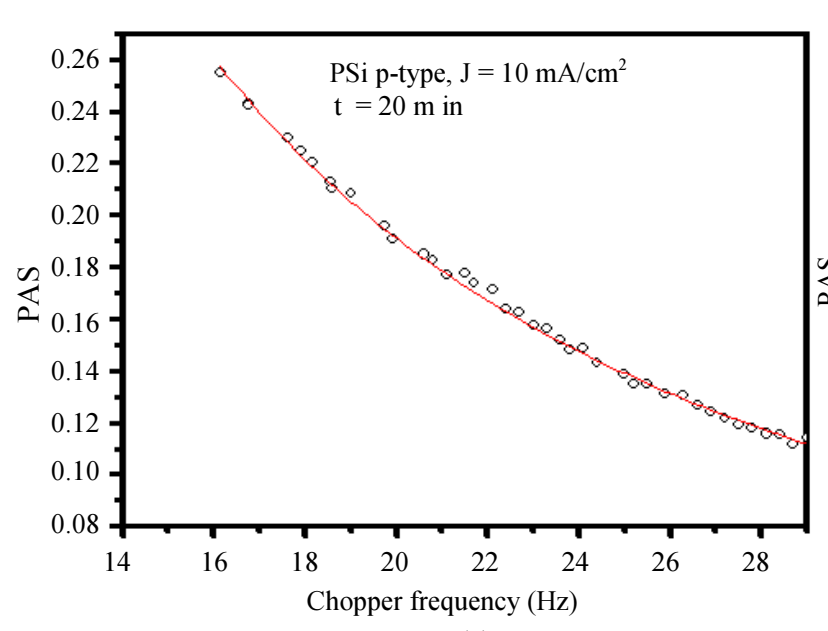

(e)

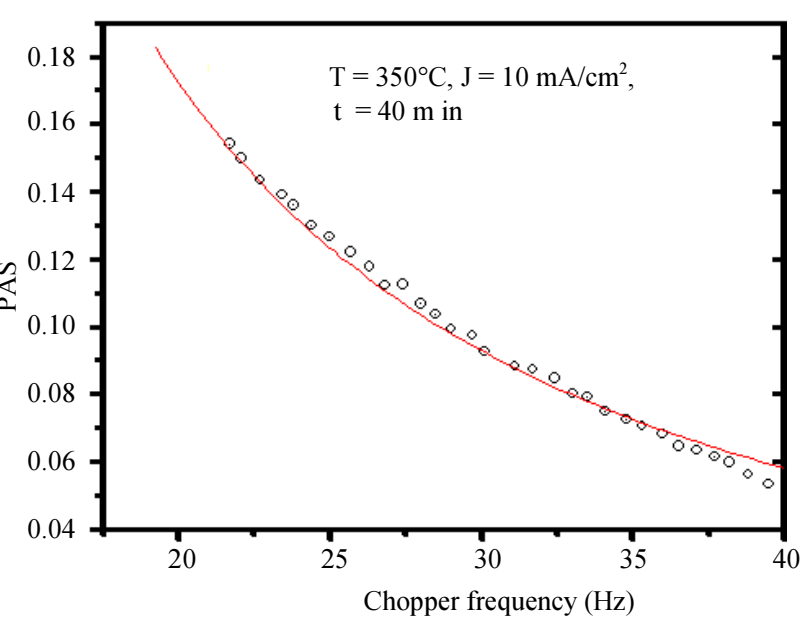

(f)

Fig. 4: PA signal versus frequency for PSi samples prepared at different etching times and varying current density under annealing high temperature for $3 \mathrm{~h}$

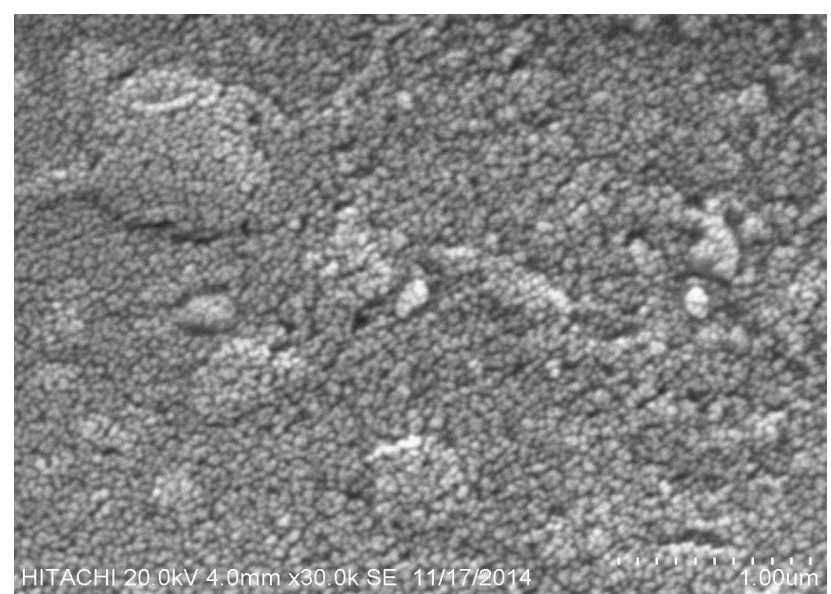

(a)

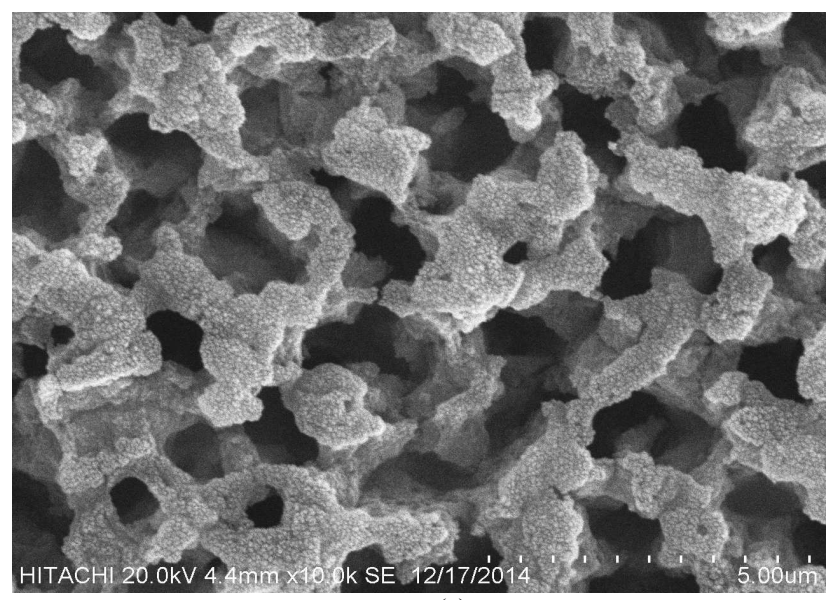

(c)

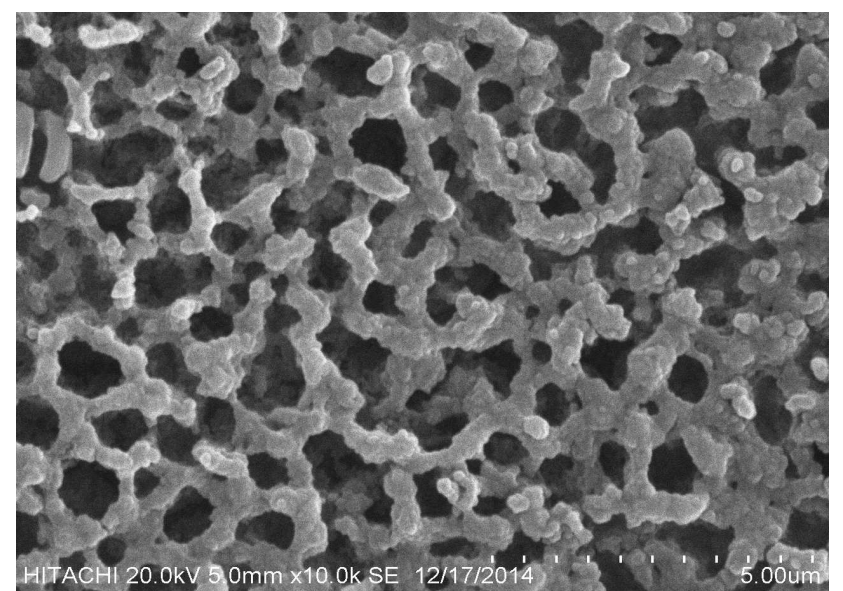

(b)

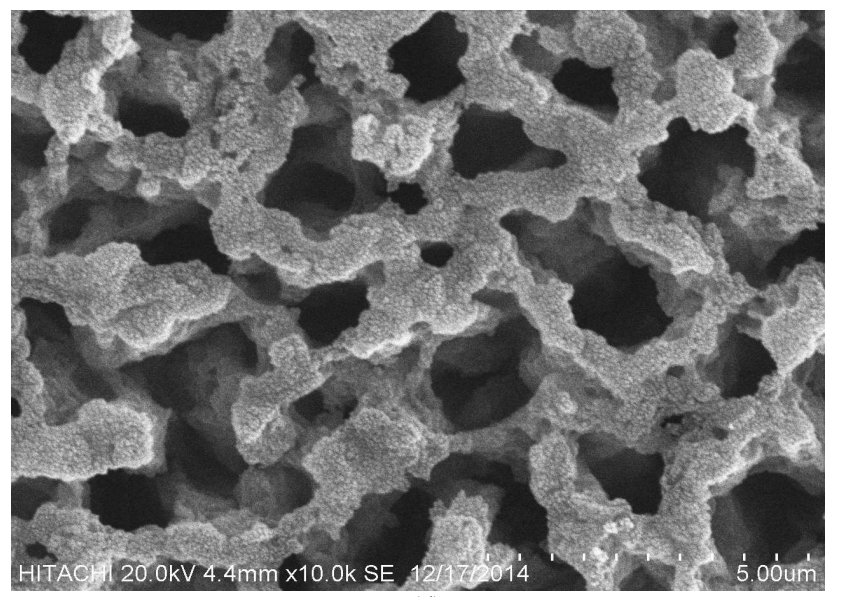

(d)

Fig. 5: SEM images of PSi samples with a different part of the surface; (a) PSi sample $\mathrm{J}=30 \mathrm{~mA} / \mathrm{cm}^{2}, \mathrm{t}=80 \mathrm{~min}$ before annealing, (b) $100^{\circ} \mathrm{C}$, (c) $200^{\circ} \mathrm{C}, 350^{\circ} \mathrm{C}$, for $3 \mathrm{~h}$ heating 
Table 1: Comparison of the measured values for TD, current density, etching time and porosity of PSi samples

\begin{tabular}{llllllr}
\hline $\mathrm{J} \mathrm{mA} / \mathrm{cm}^{2}$ & $\mathrm{t} \mathrm{min}$ & $1_{\mathrm{s}} \mu \mathrm{m}$ & $\mathrm{P}(\%)$ & $\mathrm{TD} \mathrm{cm} / \mathrm{s} \mathrm{T}=100^{\circ} \mathrm{C}$ & $\mathrm{TD} \mathrm{cm} / \mathrm{s} \mathrm{T}=200^{\circ} \mathrm{C}$ & $\mathrm{TD} \mathrm{cm}^{2} / \mathrm{s} \mathrm{T}=350^{\circ} \mathrm{C}$ \\
\hline 10 & 20 & 4.0 & 20.30 & 0.0012 & 0.0013 & 0.0015 \\
& 40 & 9.4 & 40.60 & 0.0026 & 0.0045 & 0.0061 \\
& 60 & 19.9 & 48.20 & 0.0189 & 0.0189 & 0.0210 \\
& 80 & 30.8 & 56.20 & 0.0491 & 0.0531 & 0.0552 \\
20 & 20 & 16.8 & 29.04 & 0.0229 & 0.0238 & 0.0286 \\
& 40 & 22.2 & 50.30 & 0.0387 & 0.0407 & 0.0584 \\
& 60 & 34.9 & 57.60 & 0.0584 & 0.0605 & 0.0675 \\
& 80 & 45.0 & 65.80 & 0.1000 & 0.1240 & 0.1590 \\
30 & 20 & 27.4 & 38.20 & 0.0496 & 0.0565 & 0.0601 \\
& 40 & 33.2 & 59.60 & 0.0544 & 0.0666 & 0.1000 \\
& 60 & 43.8 & 68.70 & 0.1200 & 0.1320 & 0.1520 \\
& 80 & 58.8 & 78.20 & 0.1920 & 0.1940 & 0.2000 \\
\hline
\end{tabular}

\section{Conclusion}

Temperature plays major important factor to change TD for the materials. In these experiments PSi samples were prepared by electrochemical method, the porosity is related to current density and etching time; the porosity increased when both are increased. Also, TD decreased with increasing annealing temperature. The porosity is related to current density and etching time. Results show that TD is also related to current density and etching time at high annealing temperatures. It was found that TD increased from 0.0012 to 0.0552 for etching time of $10 \mathrm{~min}$ to $80 \mathrm{~min}$.

\section{Acknowledgment}

The authors would like to thank Electro-Optic Centre, Directorate of Material Research, Ministry of Science and Technology, Iraq for providing the research facilities.

\section{Author's Contributions}

Mohammed Jabbar Hussein: Corresponding author. Suaad Sahib Hindal: experimental.

Amany Akram Awad: Writing and experimental.

\section{Ethics}

Authors should address any ethical issues that may arise after the publication of this manuscript.

\section{References}

Aamodt, L. C. and J.C. Murphy, 1981. Photothermal measurements using a localized excitation source. J. Applied Phys., 52: 4903-4914. DOI: 10.1063/1.329451

Almond, D.P. and P. Patel, 1996. Photothermal Science and Techniques. 1st Edn., Springer Science and Business Media, London, ISBN-10: 0412578808, pp: 241.

Behzad, W.M., M. Yunus, Z.A. Talib, A. Zakaria and A. Bahrami, 2012. Preparation and thermal characterization of annealed gold coated porous silicon. Materials, 5: 157-168.

DOI: $10.3390 / \mathrm{ma} 5010157$
Bisi, O., S. Ossicini and L. Pavesi, 2000. Porous silicon: A quantum sponge structure for silicon based optoelectronics. Surface Sci. Reports, 38: 1-126. DOI: 10.1016/S0167-5729(99)00012-6

El-Brolossy, T., 2012. Photoacoustic measurements of optical energy gap of porous silicon as a two layer opaque material. Indian J. Phys., 86: 39-44.

DOI: $10.1007 / \mathrm{s} 12648-012-0008-3$

Favier, J.P., 1997. Photothermal experiments on condensed phase samples of agricultural interest: Optical and thermal characterization.

Gupta, P., A.C. Dillon, A.S. Bracker and S.M. George, 1991. FTIR studies of $\mathrm{H}_{2} \mathrm{O}$ and $\mathrm{D}_{2} \mathrm{O}$ decomposition on porous silicon surfaces. Surface Sci., 245: 360-372. DOI: 10.1016/0039-6028(91)90038-T

Hussein, M.J., W.M.M. Yunus, H.M. Kamari and A. Zakaria, 2015a. Thermal diffusivity measurement for p-Si and Ag/p-Si by Photoacoustic technique. Brazil. J. Phys., 45: 518-524. DOI: 10.1007/s13538-015-0343-x

Hussein, M.J., W.M.M. Yunus., H. Mohamed and A.Z. Kamari, 2015b. Thermal diffusivity measurement of porous Siliconlayer (p-type) using photo-acoustic technique. Int. J. Adv. Sci. Eng. Technol., 3: 65-68.

Hussein, M.J., W.M.M. Yunus, H.M. Kamari, A. Zakaria and H.F. Oleiw, 2016. Effect of current density and etching time on photoluminescence and energy band gap of p-type porous silicon. Optical Quantum Electron., 48: 1-8. DOI: 10.1007/s1 1082-016-0476-3

McDonald, F.A. and G.C. Wetsel Jr, 1978. Generalized theory of the photoacoustic effect. J. Applied Phys., 49: 2313-2322. DOI: $10.1063 / 1.325116$

Rosencwaig, A. and A. Gersho, 1976. Theory of the photoacoustic effect with solids. J. Applied Phys., 47: 64-69. DOI: 10.1063/1.322296

Raveendranath, J. Ravi, S. Jayalekshmi, T. Rasheed, and K. Nair, 2006. Thermal diffusivity measurement on $\mathrm{LiMn}_{2} \mathrm{O}_{4}$ and its de-lithiated form $\left(\lambda-\mathrm{MnO}_{2}\right)$ using photoacoustic technique. Mater. Sci. Eng. B, 131: 210-215. DOI: 10.1016/j.mseb.2006.04.012 
Striemer, C.C. and P.M. Fauchet, 2002. Dynamic etching of silicon for broadband antireflection applications. Applied Phys. Lett., 81: 2980-2982.

DOI: $10.1063 / 1.1514832$
Perondi, L.F. and L.C. Miranda, 1987. Minimal-volume photoacoustic cell measurement of thermal diffusivity: Effect of the thermoelastic sample bending. J. Applied Phys., 62: 2955-2959. DOI: 10.1063/1.339380 